\title{
Glucose-6-phosphate dehydrogenase deficiency among children attending the Emergency Paediatric Unit of Usmanu Danfodiyo University Teaching Hospital, Sokoto, Nigeria
}

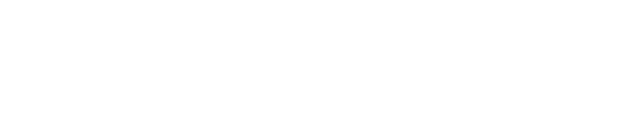

IZ Isaac'

AS Mainasara ${ }^{2}$

Osaro Erhabor ${ }^{1}$

ST Omojuyigbe'

MK Dallatu ${ }^{3}$

LS Bilbis ${ }^{3}$

TC Adias ${ }^{4}$

'Department of Haematology and Transfusion Medicine, ${ }^{2}$ Department of Chemical Pathology, ${ }^{3}$ Department of Biochemistry, Usmanu Danfodiyo University, Sokoto, Nigeria; ${ }^{4}$ Bayelsa State College of Health Technology, Ogbia, Nigeria
Correspondence: Erhabor Osaro Department of Haematology and Transfusion Medicine, Faculty of Medical Laboratory Science, College of Health Sciences, Usmanu Danfodiyo University, Sokoto, Nigeria

Email n_osaro@yahoo.com

\begin{abstract}
Glucose-6-phosphate dehydrogenase (G6PD) deficiency is one of the most common human enzyme deficiencies in the world. It is particularly common in populations living in malaria-endemic areas, affecting more than 400 million people worldwide. This present study was conducted with the aim of determining the prevalence of G6PD deficiency among children visiting the Emergency Paediatric Unit of Usmanu Danfodiyo University Teaching Hospital for pediatric-related care. The study included 118 children, made up of 77 (65.3\%) males and $41(34.7 \%)$ females aged $\leq 5$ years with mean age of $3.26 \pm 1.90$ years. Randox G6PD quantitative in vitro test screening was used for the diagnosis of G6PD deficiency. Of the 118 children tested, 17 (14.4\%) were G6PD-deficient. Prevalence of G6PD deficiency was concentrated predominantly among male children (22.1\%). Male sex was significantly correlated with G6PD deficiency among the children studied $(r=7.85, P=0.01)$. The highest prevalence occurred among children in the 2- to 5-year age-group. Of the 17 G6PD-deficient children, twelve $(70.2 \%)$ were moderately deficient, while five (29.4\%) were severely deficient. Blood film from G6PDdeficient children indicated the following morphological changes; Heinz bodies, schistocytes, target cells, nucleated red cells, spherocytes, and polychromasia. This present study has shown a high prevalence of G6PD deficiency among children residing in Sokoto in the northwestern geopolitical zone of Nigeria. The study indicated a male sex bias in the prevalence of G6PD deficiency among the children studied. There is a need for the routine screening of children for G6PD deficiency in our environment, to allow for evidence-based management of these children and to ensure the avoidance of food, drugs, and infective agents that can potentially predispose these children to oxidative stress as well as diseases that deplete micronutrients that protect against oxidative stress. There is need to build capacity in our setting among pediatricians to ensure the effective management of children with G6PD deficiency.
\end{abstract}

Keywords: G6PD, children, emergency pediatric unit, Usmanu Danfodiyo University Teaching Hospital, Sokoto, Nigeria

\section{Introduction}

Glucose-6-phosphate dehydrogenase (G6PD) deficiency is the most common human enzyme defect, being present in more than 400 million people worldwide. ${ }^{1}$ G6PD deficiency is common in African patients with malaria, and G6PD status does not impact baseline hemoglobin, parasitemia, or temperature, or the outcomes of antimalarial therapy. During G6PD deficiency, the red cells are unable to regenerate reduced nicotinamide adenine dinucleotide phosphate (NADPH), a reaction that is normally 
catalyzed by the G6PD enzyme. Since the X chromosome carries the gene for G6PD enzyme, this deficiency mostly affects males. The two major conditions associated with G6PD deficiency are hemolytic anemias and neonatal jaundice, which may result in neurological complications and death. Screening and detection of G6PD deficiency helps in reducing such episodes, through appropriate selection of treatment, patient counseling, and abstinence from diseaseprecipitating drugs such as antimalarials and other agents. G6PD is an enzyme present in the cytoplasm of all cells, acting specifically in the maintenance of the integrity of the erythrocytes, preventing the oxidation of hemoglobin and other cellular proteins. In Nigeria, the prevalence of G6PD deficiency ranges from $4 \%$ to $26 \% .^{2-4}$ A study by Akanni et al in Oshogbo, Nigeria among 200 blood donors and 86 jaundiced neonates indicated G6PD deficiencies of $19.5 \%$ and $47.7 \%$, respectively. ${ }^{5}$ G6PD deficiency occurs most frequently in individuals of African descent, with frequency ranging from $3.6 \%$ to $28.0 \%{ }^{6}$ In Asia, the deficiency prevalence ranges from $6.0 \%$ to $15.8 \% .^{7,8}$ In India, ${ }^{9}$ it is $10.5 \%$, and in the Middle East ${ }^{10,11}$ the prevalence varies from $3 \%$ to $29 \%$. In Brazil, a few studies have found prevalences between $1.7 \%$ and $6.0 \% .^{12-14}$

There is a paucity of data on G6PD deficiency among children in the northwest geopolitical zone of Nigeria. The clinical effect of G6PD deficiency in children in Sokoto metropolis is unknown. There is a lack of local evidencebased data required for the management of children with G6PD deficiency in the area. This study was specifically aimed at determining the prevalence of G6PD deficiency among children visiting the Emergency Pediatric Unit of Usmanu Danfodiyo University Teaching Hospital for pediatric-related care.

\section{Materials and methods Study design}

This was a prospective case study designed to assess the prevalence of G6PD deficiency among 118 children: made up of $77(65.3 \%)$ males and 41 (34.7\%) females aged $\leq 5$ years (mean age $3.26 \pm 1.90$ years), who were consecutively recruited from among children attending the Emergency Paediatric Unit of Usmanu Danfodiyo University Teaching Hospital for pediatric care between January to September 2011. No medical criteria were used to select the subjects. Written informed consent was obtained from parents after counseling. Parents of all participants were counseled and those who consented (written informed consent) to their children being part of the study were recruited. Ethical clearance was obtained from the ethical review board of the Department of Haematology and Transfusion Medicine, Usmanu Danfodiyo University, Sokoto, Nigeria.

\section{Study area}

This research was carried out at the Usmanu Danfodiyo University Teaching Hospital in the cosmopolitan city of Sokoto in northwestern Nigeria. The hospital is a 500bed tertiary health facility offering routine and specialist pediatric care to children in the Sokoto metropolis and the surrounding states of Kebbi and Zamfara. Sokoto State is located in the extreme northwest of Nigeria, near the confluence of the Sokoto River and the Rima River. With an annual average temperature of $28.3^{\circ} \mathrm{C}\left(82.9^{\circ} \mathrm{F}\right)$, Sokoto is, on the whole, a very hot area. However, maximum daytime temperatures are generally under $40^{\circ} \mathrm{C}\left(104.0^{\circ} \mathrm{F}\right)$ for most of the year. The warmest months are February to April, when daytime temperatures can exceed $45^{\circ} \mathrm{C}\left(113.0^{\circ} \mathrm{F}\right)$. The rainy season is from June to October, during which showers are a daily occurrence. There are two major seasons, wet and dry, which are distinct and are characterized by high and low malarial transmission, respectively. A report from the 2007 National Population Commission indicated that the state had a population of 3.6 million. ${ }^{15}$

\section{Sample collection and methods}

Three milliliters of whole blood was collected from each study participants into S-Monovette (Sarstedt, Nümbrecht, Germany) ethylenediaminetetraacetic acid (EDTA)-anticoagulated vacutainer tubes $(2.7 \mathrm{~mL})$. The EDTA-anticoagulated blood was used for the screening of the subjects for G6PD deficiency using the Randox G6PD quantitative in vitro test (Randox Laboratories, Crumlin, UK). Its principle is based on reduction of $\mathrm{NADP}^{+}$by G6PD present in red blood cells. The NADPH generated fluoresces under ultraviolet light at a wave length of $340 \mathrm{~nm}$. Enzyme activity was determined by the rate of absorbance change. Red blood cell G6PD value of $\geq 2.9 \mathrm{U} / \mathrm{gHb}$ was regarded as normal. ${ }^{16}$ Children with red blood cell G6PD value of $<2.9 \mathrm{U} / \mathrm{gHb}$ were regarded as deficient, while those with red blood cell G6PD value of $<1.6 \mathrm{U} / \mathrm{gHb}$ were regarded as severely deficient. This assay is useful clinically in the diagnosis of G6PD deficiency in childhood. Blood film was prepared using the push-wedge method and stained using a Romanowsky stain (Leishman stain).

\section{Statistical analysis}

Statistical analyses were conducted using SPSS (version 11; IBM, Armonk, NY, USA) software. Data were expressed as 
means \pm standard deviation. Comparisons between G6PDdeficient and nondeficient children were made using Student's $t$-test for parametric data and the Mann-Whitney test for nonparametric data. Descriptive analyses of percentages of categorical variables were reported. An alpha value of $<0.05$ denoted a statistically significant difference in all statistical comparisons. Correlation was compared using a version of linear regression analysis.

\section{Results}

This present study was conducted with the aim of determining the prevalence of G6PD deficiency among children visiting the Emergency Paediatric Unit of Usmanu Danfodiyo University Teaching Hospital for pediatric-related care. The study included 118 children made up of 77 (50.9\%) males and 41 (34.8\%) females aged $\leq 5$ years with a mean age of $3.26 \pm 1.90$ years. Table 1 shows the distribution of G6PD deficiency based on sex of the children studied. The Randox G6PD quantitative in vitro test was used for the diagnosis of G6PD deficiency. Of the 118 children tested, 17 (14.4\%) were G6PD-deficient. Prevalence of G6PD deficiency was concentrated predominantly among male children 17 (22.1\%).

None of the female subjects was G6PD-deficient. Male sex was significantly correlated with G6PD deficiency among the children studied $(r=7.85, P=0.01)$. The highest prevalence occurred among children in the 2- to 5-year age-group. Of the 17 G6PD-deficient children, twelve $(70.2 \%)$ were moderately deficient, while five $(29.4 \%)$ were severely deficient. Figure 1 shows the distribution of G6PD deficiency based on age-groups. Blood film from G6PDdeficient children indicated the following morphological changes; Heinz bodies, schistocytes, target cells, nucleated red cells, spherocytes, and polychromasia. Figure 2 shows a characteristic blood picture of one of the G6PD-deficient subjects.

\section{Discussion}

G6PD deficiency is one of the most common human enzyme deficiencies in the world. In this study, we observed a prevalence of $14.4 \%$ among the children studied. Our finding

Table I Distribution of G6PD deficiency based on sex

\begin{tabular}{lll}
\hline Sex & Number (\%) & $\begin{array}{l}\text { Number (\%) G6PD-deficient } \\
(<2.9 \text { U/gHb) }\end{array}$ \\
\hline Male & $77(65.3)$ & $17(22.1)$ \\
Female & $41(34.7)$ & $0(0.0)$ \\
Total & $118(100.00)$ & $17(14.4)$ \\
\hline
\end{tabular}

Abbreviation: G6PD, glucose-6-phosphate dehydrogenase.

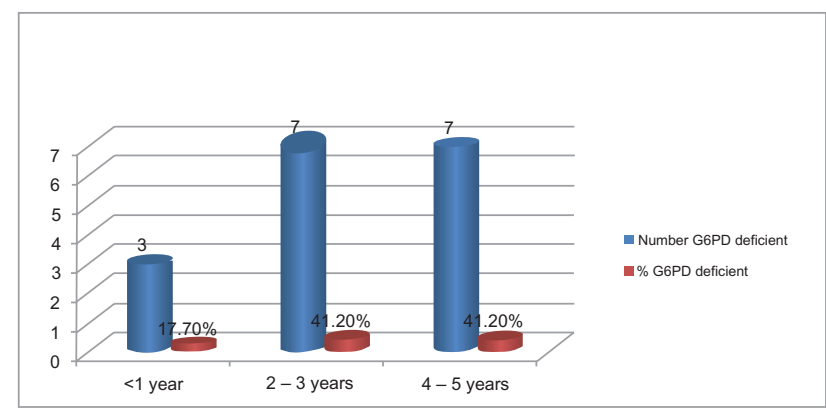

Figure I Sex distribution of G6PD deficiency among subjects. Abbreviation: G6PD, glucose-6-phosphate dehydrogenase.

is consistent with previous reports in Nigeria and other parts of the world. In previous reports in Nigeria, the prevalence of G6PD deficiency ranged from $4 \%$ to $26 \% .^{2-4}$ However, a study by Akanni et $\mathrm{al}^{5}$ in Oshogbo, Nigeria among 200 blood donors and 86 jaundiced neonates indicated G6PD deficiencies of $19.5 \%$ and $47.7 \%$, respectively. African, Middle Eastern, and South Asian people are affected the most, along with those who are a mixed race with any of the above. G6PD deficiency occurs most frequently in individuals of African descent, with a frequency ranging from $3.6 \%$ to $28.0 \%{ }^{5,6}$ In Asia, the deficiency prevalence ranges from $6.0 \%$ to $15.8 \%{ }^{7,8}$ In India, it is $10.5 \%,{ }^{9}$ while in the Middle East the prevalence varies from $3 \%$ to $29 \%{ }^{10,11}$ In Brazil, a few studies have found prevalences between $1.7 \%$ and $6.0 \% .{ }^{12-14}$ There may be several reasons for the high prevalence of G6PD, particularly among children 2-5 years old in this environment. There is a high incidence of malaria parasitemia in our setting. G6PD deficiency is believed to offer protection against the most deadly plasmodium - falciparum malaria. ${ }^{17}$

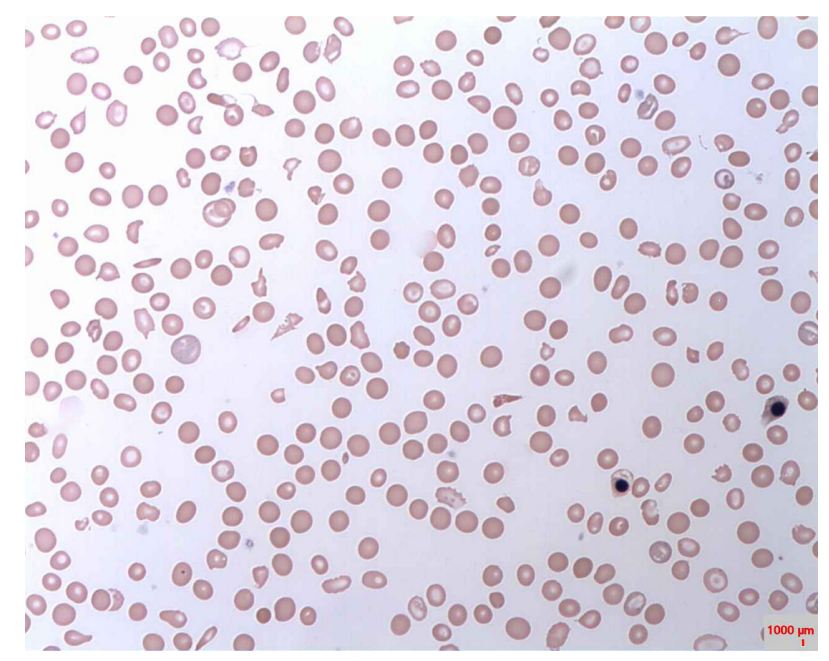

Figure 2 A characteristic blood film from one of the glucose-6-phosphate dehydrogenase-deficient children. 
A side effect of G6PD deficiency is that it confers protection against malaria. ${ }^{18}$ One theory to explain this protection is that cells infected with the Plasmodium parasite are cleared more rapidly by the spleen. This phenomenon may be responsible for the evolutionary advantage and fitness that G6PDH deficiency carriers enjoy in malarial endemic environments. High prevalence of hemoglobinopathies in our setting may also be a predisposing factor for the increased prevalence of G6PD deficiency. A number of epidemiological studies have associated sickle-cell trait (SCT) or G6PD deficiency with protection against malaria, in particular severe, lifethreatening malaria in its cerebral form. SCT and G6PD deficiency are two common genetic conditions in sub-Saharan Africa. ${ }^{19}$ G6PD is an enzyme that catalyzes the first step of the pentose phosphate pathway and supports the production of reduced glutathione, a major defense against oxidant stress in red blood cells. A number of epidemiological studies have associated SCT or G6PD deficiency with protection against malaria, in particular severe, life-threatening malaria in its cerebral form. ${ }^{20,21}$

G6PD deficiency is an X-linked condition associated with damage to red blood cells and hemolysis in response to a variety of exposures, including infection, ingestion of fava beans, or exposure to certain chemicals or medications. Drug-induced acute hemolytic anemia led to the discovery of G6PD deficiency. A significant number of foods (fava beans) and such medications as antimalarial drugs (primaquine, chloroquine, and pamaquine), sulfonamides (sulfanilamide, sulfamethoxazole, and mafenide), analgesics (aspirin, phenazopyridine, and acetanilide), nonsulfa antibiotics (nalidixic acid, nitrofurantoin, isoniazid, dapsone, and furazolidone) that are commonly used in the management of illnesses in our environment are potentially harmful to people with G6PD deficiency. ${ }^{22-26}$

We observed a male-dominated prevalence of G6PD deficiency. All the G6PD-deficient subjects were male. No female subject studied was G6PD-deficient. G6PD deficiency is one of the most common human enzyme deficiencies in the world. During G6PD deficiency, the red cells are unable to regenerate reduced NADPH, a reaction that is normally catalyzed by the G6PD enzyme. G6PD deficiency is an $\mathrm{X}$-linked recessive hereditary disease characterized by abnormally low levels of G6PD. The deficiency is X-linked since the $\mathrm{X}$ chromosome carries the gene for G6PD enzyme; this deficiency mostly affects males. G6PD deficiency is inherited from females who carry one copy of the causative gene on one of their X chromosomes. Males who inherit the causative gene from the mother have G6PD deficiency, while females who receive the gene are carriers (carrier females generally do not show any characteristic symptoms). The deficiency is rare in females because the mutation would have to occur in both copies of the gene to cause the disorder, whereas in males only one abnormal copy of the gene is required for manifestation of the disease. This is consistent with previous reports that indicated that the sex of the patient is important and that males are at greater risk based on severity compared to females. ${ }^{27-30}$ It is, however, at variance with a previous report ${ }^{31}$ assessing the frequency of G6PD deficiency in Sardinian patients with nonarteritic anterior ischemic optic neuropathy, which indicated based on sex and G6PDdeficiency interaction that sex does not have any modifier effect on G6PD deficiency. Also, another report ${ }^{32}$ among children in Malaysia indicated that sex was not a significant predictor associated with actual G6PD enzyme levels.

A significant number of subjects with G6PD deficiency in this study were in the 2- to 3-and 4- to 5-year age-groups. This finding re-emphasizes the need for the health ministry in Nigeria to set up a national neonatal screening program for presumptive screening of all neonates to facilitate the identification and effective management of children with G6PD deficiency. The screening program should be introduced in all tertiary hospitals in the major cities and then gradually scaled up to cover institutional deliveries over the entire country. Evidence from other nations indicates that neonatal screening programs are vital to manage the public health burden of G6PD in a population. Neonatal screening programs for the condition have the potential to increase parental and caretaker awareness, thereby facilitating early access to treatment, with resultant diminished mortality and morbidity. ${ }^{33-36}$ Evidence-based management of G6PD should include the prevention or avoidance of the drugs and foods that predispose patients to hemolysis, protective vaccination (hepatitis A and B), provision of safe and adequate units of red cell transfusion to manage acute hemolysis in acutely affected children, and provision of effective dialysis services to treat acute renal failure. Splenectomy may also be an option and may be beneficial in some children, as well as supplementation with such antioxidant drugs as vitamin E, selenium, and folic acid.

\section{Conclusion}

This study has shown a high prevalence of G6PD deficiency among children residing in Sokoto in northwestern Nigeria. Findings indicated a male-sex bias in the prevalence of G6PD deficiency among the children studied. There is a need for the routine screening of children for G6PD deficiency in 
our environment to allow for evidence-based management of these children, to ensure the avoidance of food and substances that can potentially predispose them to oxidative stress, as well as other diseases that deplete micronutrients that protect against oxidative stress. There is also a need to offer protective vaccination against hepatitis A and B to affected children against infection-induced attacks. There is also a need to build capacity among pediatricians in our setting to ensure the effective management of children with G6PD deficiency.

\section{Acknowledgments}

The authors are grateful to staff of the Haematology and Blood Transfusion, Chemical Pathology, and Paediatrics Departments of Usmanu Danfodiyo University Teaching Hospital(UDUTH), Sokoto for their support and collaboration. We are also grateful to the parents of participants in this study for their collaboration.

\section{Disclosure}

The authors hereby certify that there were no conflicts of interest in the execution of this study.

\section{References}

1. Cappellini MD, Fiorelli G. Glucose-6-phosphate dehydrogenase deficiency. Lancet. 2008;371(9606):64-74.

2. Ademowo OG, Falusi AG. Molecular epidemiology and activity of erythrocyte G6PD variants in a homogeneous Nigerian population. East Afr Med J. 2002;79(1):42-44.

3. Luzzatto L, Gordon-Smith EC. Inherited haemolytic anaemia. In: Hoffbrand AV, Lewis SM, Tuddenham EGD, editors. Postgraduate Haematology. 4th ed. London: Arnold; 2001:120-143.

4. Egesie D, Joseph DE, Isiguzoro I, Egesie UG. Glucose-6-phosphate dehydrogenase (G6PD) activity and deficiency in a population of Nigerian male residents in Jos. Niger J Physiol Sci. 2008;23(1-2):9-11.

5. Akanni EO, Oseni BSA, Agbona VO, et al. Glucose-6-phosphate dehydrogenase deficiency in blood donors and jaundiced neonates in Osogbo, Nigeria. J Med Lab Diagn. 2010;1(1):1-4.

6. De Araujo C, Migot-Nabias F, Guitard J, Pelleau S, Vulliamy T, Ducrocq R. The role of the G6PD AEth376G/968C allele in glucose6-phosphate dehydrogenase deficiency in the Seerer population of Senegal. Haematologica. 2006;91(2):262-263.

7. Iwai K, Hirono A, Matsuoka H, et al. Distribution of glucose-6phosphate dehydrogenase mutations in Southeast Asia. Hum Genet. 2001;108(6):445-449.

8. Louicharoen C, Nuchprayoon I. G6PD Viangchan $(871 \mathrm{G}>A$ A) is the most common G6PD-deficient variant in the Cambodian population. J Hum Genet. 2005;50(9):448-452.

9. Sukumar S, Mukherjee MB, Colah RB, Mohanty D. Molecular basis of G6PD deficiency in India. Blood Cells Mol Dis. 2004;33(2):141-145.

10. Al-Riyami A, Ebrahim GJ. Genetic blood disorders survey in the sultanate of Oman. J Trop Pediatr. 2003;49 Suppl 1:i1-i20.

11. Usanga EA, Ameen R. Glucose-6-phosphate dehydrogenase deficiency in Kuwait, Syria, Egypt, Iran, Jordan and Lebanon. Hum Hered. 2000;50(3):158-161.

12. Compri MB, Saad ST, Ramalho AS. Genetic-epidemiological and molecular investigation of G-6-PD deficiency in a Brazilian community. Cad Saude Publica. 2000;16(2):335-342. Portuguese.
13. Castro S, Weber R, Dadalt V, Tavares V, Giugliani R. Prevalence of G6PD deficiency in newborns in the south of Brazil. J Med Screen. 2006;13(2):85-86.

14. Santana MS, de Lacerda MVG, Barbosa MdGV, Alecrim WD, Alecrim MdGC. Glucose-6-phosphate dehydrogenase deficiency in an endemic area for malaria in Manaus: a cross-sectional survey in the Brazilian Amazon. PLoS One. 2009;4(4):e5259.

15. National Population Commission (NPC). National census figures, Abuja, Nigeria. 2007.

16. Obasa TO, Mokuolu OA, Ojuuawo A. Glucose 6 phosphate dehydrogenase levels in babies delivered at the University of Ilorin Teaching Hospital. Niger J Paediatr. 2011;38(4):165-169.

17. Tine RC, Ndiaye M, Hansson HH, et al. The association between malaria parasitaemia, erythrocyte polymorphisms, malnutrition and anaemia in children less than 10 years in Senegal: a case control study. BMC Res Notes. 2012;5:565.

18. Mehta A, Mason PJ, Vulliamy TJ. Glucose-6-phosphate dehydrogenase deficiency. Baillieres Best Pract Res Clin Haematol. 2000;13(1):21-38.

19. Guindo A, Traore K, Diakite S, Wellems TE, Doumbo OK, Diallo DA. An evaluation of concurrent G6PD (A-) deficiency and sickle cell trait in Malian populations of children with severe or uncomplicated P. falciparum malaria. Am J Hematol. 2011;86(9):795-796.

20. Ruwende C, Khoo SC, Snow RW, et al. Natural selection of hemi- and heterozygote for G6PD deficiency in Africa by resistance to severe malaria. Nature. 1995;376(6537):246-249.

21. Guindo A, Fairhurst RM, Doumbo OK, Wellems TE, Diallo DA. X-linked G6PD deficiency protects hemizygous males but not heterozygous females against severe malaria. PloS Med. 2007;4(3):e66.

22. Arese P, Mannuzzul L, Turrini F, et al. Etiological aspects of favism. In: Yoshida A, Beutler E, editors. Glucose-6-Phosphate Dehydrogenase. Orlando: Academic Press; 1986:45-75.

23. Müller O, Mockenhaupt FP, Marks B, et al. Haemolysis risk in methylene blue treatment of G6PD-sufficient and G6PD-deficient West-African children with uncomplicated falciparum malaria: a synopsis of four RCTs. Pharmacoepidemiol Drug Saf. 2013;22(4):376-385.

24. Carter N, Pamba A, Duparc S, Waitumbi JN. Frequency of glucose6-phosphate dehydrogenase deficiency in malaria patients from six African countries enrolled in two randomized anti-malarial clinical trials. Malar J. 2011;10:241.

25. Guellouz N, Ben Mansour I, Ouederni M. Neonatal screening of G6PD deficiency in Tunisia. Arch Inst Pasteur Tunis. 2010;87(1-2):69-76. French.

26. Pamba A, Richardson ND, Carter N, et al. Clinical spectrum and severity of haemolytic anaemia in glucose-6-phosphate dehydrogenase-deficient children receiving dapsone. Blood. 2012;120(20):4123-4133.

27. Munyanganizi R, Cotton F, Vertongen F, et al. Red blood cell disorders in Rwandese neonates: screening for sickle cell disease and glucose-6-phosphate dehydrogenase deficiency. J Med Screen. 2006;13(3):129-131.

28. Kaplan M, Hammerman C, Vreman HJ, Stevenson DK, Beutler E. Acute hemolysis and severe neonatal hyperbilirubinemia in glucose6-phosphate dehydrogenase deficient heterozygotes. J Pediatr. 2001;139(1):137-140.

29. Cohan N, Karimi M, Khalili AH, Falahzadeh MH, Samadi B, Mahdavi MR. The efficacy of a neonatal screening programme in decreasing the hospitalization rate of patients with G6PD deficiency in southern Iran. J Med Screen. 2010;17(2):66-67.

30. Padilla C, Nishiyama K, Shirakawa T, Matsuo M. Screening for glucose-6-phosphate dehydrogenase deficiency using a modified formazan method: a pilot study on Filipino male newborns. Pediatr Int. 2003;45(1):10-15.

31. Pinna A, Solinas G, Masia C, Zinellu A, Carru C, Carta A. Glucose-6-phosphate dehydrogenase (G6PD) deficiency in nonarteritic anterior ischemic optic neuropathy in a Sardinian population, Italy. Invest Opthalmol Vis Sci. 2008;49(4):1328-1232. 
32. Wang FL, Boo NY, Ainoon O, Wong MK. Comparison of detection of glucose-6-phosphate dehydrogenase deficiency using fluorescent spot test, enzyme assay and molecular method for prediction of severe neonatal hyperbilirubinaemia. Singapore Med J. 2009;50(1):62-67.

33. Nair H. Neonatal screening program for G6PD deficiency in India: need and feasibility. Indian Pediatr. 2009;46(12):1045-1049.

34. Chiang SH, Wu SJ, Wu KF, Hsiao KJ. Neonatal screening for glucose6-phosphate dehydrogenase deficiency in Taiwan. Southeast Asian J Trop Med Public Health. 1999;30 Suppl 2:72-74.
35. Chuu WM, Lin DT, Lin KH, Chen BW, Chen RL, Lin KS. Can severe neonatal jaundice be prevented by neonatal screening for glucose-6phosphate dehydrogenase deficiency? A review of evidence. Zhonghua Min Guo Xiao Er Ke Yi Xue Hui Za Zhi. 1996;37(5):333-341.

36. Kaplan M, Hammerman C. Neonatal screening for glucose-6-phosphate dehydrogenase deficiency: biochemical versus genetic technologies. Semin Perinatol. 2011;35(3):155-156.

\section{Publish your work in this journal}

The International Journal of General Medicine is an international, peer-reviewed open-access journal that focuses on general and internal medicine, pathogenesis, epidemiology, diagnosis, monitoring and treatment protocols. The journal is characterized by the rapid reporting of reviews, original research and clinical studies across all disease areas.
A key focus is the elucidation of disease processes and management protocols resulting in improved outcomes for the patient. The manuscript management system is completely online and includes a very quick and fair peer-review system. Visit http://www.dovepress.com/ testimonials.php to read real quotes from published authors.

Submit your manuscript here: http://www.dovepress.com/international-journal-of-general-medicine-journal 